\title{
PERAN GAYA KOMUNIKASI TERHADAP MOTIVASI PADA INDUSTRI MANUFAKTUR OTOMOTIF DI KOTA TANGERANG
}

\author{
Joni Prihatin ${ }^{1}$, Uli Wildan Nuryanto ${ }^{2}$, Muhammad Suparmoko ${ }^{3}$ \\ 1,2,3 Universitas Bina Bangsa \\ joniprihatinjepe@gmail.com
}

\begin{abstract}
ABSTRAK
Sektor indutri otomotif yang berkembang pesat di Indonesia sejak tahun 1970 telah membawa dampak positif terhadap perekonomian Tanah Air. Sumbangsih GDP yang tinggi dan menjadi mampu menjadi lapangan pekerjaan sebesar 350 ribu orang tenaga kerja langsung dan 1,2 juta orang tenaga kerja tidak langsung. Oleh karena itu sektor ini perlu didukung agar terus maju dan berkembang, salah satunya adalah dengan pengelolaan sumber daya manusia dengan meningkatkan motivasi kerja para pekerjanya dimana variabel ini dipengaruhi oleh banyak hal salah satunya dalah dengan gaya komunikasi. Penelitian ini dilakukan dengan menggunakan pendekatan kuantitatif menggunakan metode survey dan desain kausalitas dengan Teknik analisis data SEM PLS. sampel yang dugunakan sebanyak 160 responden dengan jumlah hipotesis yang diujikan sebanyak 6 hipotesis. Hasil penelitian didapatkan dari kedua variabel terdapat 3 indikator yang tidak valid karen nilai loading faktornya <0,70 sehingga di droping dari model. Untuk hasil outer model analisis dan inner model analisis model ke-2 didapatkan seluruh parameter telah sesuai dengan yang dipersyaratkan. Hasil uji hipotesis didapatkan seluruh hipotesis yang diujikan dapat diterima. Gaya komunikasi berpengaruh signifikan terhadap motivasi kerja dengan besarnya pengaruh sebesar 51,1\% sedangkan sisanya sebesar 48,9\% dipengaruhi variabel lainnya diluar model yang diujikan.
\end{abstract}

Kata Kunci: Gaya Komunikasi, Motivasi Kerja, Sektor Industri Otomotif

\section{ABSTRACT}

The Automotive sector industry has grown rapidly since 1970 had a positive impact on the country's economy which are high GDP contribution and being able to become a job field for 350 thousand of direct workers and 1,2 million of indirect workers. Therefore, this sector needs to be supported do that continues advance and develop. One of this way by management of human resources to increasingly the work motivation of its workers where this variable influenced by many things, one of which is communication style. This research was conducted using a quantitative approach using survey methods and causality design with SEM PLS data analysis techniques. The sample used 160 respondents with the number of 6 hypothesis tested. The result obtained from two variables there are 3 indicators that are not since to the loading factor $<0,70$ so those indicators excluded from the model. For the result of second model analysis, inner model analysis and blindfolding analysis of the $2^{\text {nd }}$ model, there was found that all parameters were in accordance with the requirements. The hypothesis result shows that all hypothesis tested were accepted. Communication style has a signification effect on work motivation 
Prosiding The 1st National Conference on Applied Business, Education, \& Technology (NCABET)"

Unversitas Bina Bangsa 2021

DOI Article : 10.46306/ncabet.v1i1.30

with the magnitude $51,1 \%$ while the remaining of 48,9\% influenced by others variable outside the model being tested.

Keywords: Communication Style, Work Motivations, Automotive Industry Sector

\section{PENDAHULUAN}

Sumber daya manusia merupakan salah satu modal terpenting bagi kemajuan perusahaan. Dengan sumber daya yang berkualitas akan menghasilkan kinerja yang optimal dan pada akhirnya meningkatkan kinerja perusahaan. Oleh karena itu diperlukan sebuah dorongan atau penggerak yang dapat mempengaruhi karyawan dalam menjalankan aktivitas kerjanya, dorongan tersebut adalah motivasi kerja. Pada saat seorang karyawan memiliki motivasi kerja yang tinggi dalam melakukan pekerjaan, maka kinerja yang dihasilkan akan meningkat. Dengan motivasi kerja yang tinggi maka karyawan akan memiliki kepuasan kerja yang tinggi dan mampu menyelesaikan kerjanya dengan performa maksimal.

Motivasi adalah suatu kondisi atau energi yang mendorong karyawan diarahkan untuk mencapai tujuan dari organisasi perusahaan. Sikap mental karyawan yang sednag pro dan positif terhadap pekerjaan akan mendukung terhadap hasil prestasi yang maksimal (Tasya \& Gilang, 2020). Motivasi dapat mempengaruhi peningkatan produktivitas karyawan, hal ini disebabkan motivasi akan menghasilkan suatu inspirasi, dorongan, semngat kerja dan Kerjasama yang baik sesame karyawan. Motivasi menjadi sangat penting karena dengan adanya motivasi maka perusahaan akan mendapatkan hasil kerja keras yang maksimal dari karyawannya untuk mencapai produktivitas kerj ayang tinggi (Karima et al, 2018).

Motivasi kerja yang dimiliki karyawan dipengaruhi oleh banyak factor, salah satunya adalah gaya kepemimpinan dari seorang atasan (leader). Komunikasi yang merupakan kunci esensial didalam setiap organisasi. Tidak ada seorangpun yang dalam kegiatan sehari-harinya tidak melakukan komunikasi. Komunikasi dapat terjalin, baik antara atasan dengan atasan, atasan dengan bawahan atau sesama bawahan. Walaupun saat ini metode dalam berkomunikasi sudah banyak mengalami perubahan sedikit demi sedikit akibat adanya kemajuan teknologi digital dan pandemic covid-19. Dimana pergerakan dan pertemuan forum mulai dibatasi dengan adanya pandemic dan mulai digantikan dengan menggunakan virtual, akan tetapi esensialnya tetaplah sama. Adanya interaksi antara individu dengan individu lainnya. 
Prosiding The 1st National Conference on Applied Business, Education, \& Technology (NCABET)"

Unversitas Bina Bangsa 2021

DOI Article : 10.46306/ncabet.v1i1.30

Komunikasi dapat menjadi variabel pembeda dalam suatu perusahaan, misalnya komunikasi dapat dijadikan sebagai sarana dalam mendorong mental karyawan oleh atasannya dengan cara menyampaikan harapan yang ingin dicapai oleh perusahaan namun juga dibarengi dengan harmonisasi secara intens. Untuk itulah diperlukan suatu gaya komunikasi yang dapat menjembatani antara tujuan yang ingin dikomunikasikan dengan yang diajak berkomunikasi. Dengan begitu esensialnya gaya komunikasi maka diperlukan seorang leader yang betul-betul memiliki gaya komunikasi yang sejalan dengan harapan bawahannya sehingga mampu mengarahkan bawahannya dalam melakukan tugas dan tanggung jawabnya di dalam perusahaan.

Gaya komunikasi yang baik menjadi indikator keberhasilan seorang pemimpin dalam memimpin bawahannya. Karyawan pada umumnya akan mengungkapkan bahwa penggunaan gaya komunikasi yang tidak efektif oleh atasannya menjadi suatu permasalahan yang pada akhirnya menggambarkan ketidak efektifan atasan dalam mengorganisir anak buahnya. Komunikasi yang tidak efektif sangat banyak sekali terjadi diperusahaan. Untuk mempraktikan komunikasi yang efektif maka para pemimpin membutuhkan suatu cara berkomunikasi yang baik dalam strategi mereka (Obi, 2018).

Peneliti berusaha menggali secara mendalam dan komprehensif terkait dengan gaya komunikasi dengan motivasi kerja pada industry otomotif. Sebagaimana diketahui bahwasanya industry otomotif merupakan salah satu sector penunjang perekonomian bagi negara. Industri otomotif sendiri mulai masuk ke Indonesia pada tahun 1970-an, dimana kontribusinya sangatlah besar diantaranya adalah; 1) Menjadi contributor terhadap 1,76\% GDP Tanah Air yang jika dirupiahkan senilai dengan Rp. 260,9 triliun dan salah satunya berasal dari pajak mobil. 2) Sebagai sector yang menyumbang investasi nasional, diantaranya sebesar Rp. 13 triliun berasal dari investasi asing dan Rp. 1,8 triliun berasal dari domestik. 3) memapu menjadi sector yan gmenyerap banyak jumlah tenaga kerjayaitu sebesar 350 ribu orang tenaga kerja langsung dan 1,2 juta pekerja tidak langsung. Bahkan saat ini Industri otomotif dalam negeri menjadi pasar otomotif terbesar di Asia Tenggara di atas Thailand dan Malaysia (Usman, 2020).

Telah banyak cendekiawan yang menggali terkait dengan pengaruh gaya kepemimpinan terhadap motivasi kerja diberbagai negara dan sector ekonomi yang berbeda-beda. Mehta et al (2020) dalam kajiannya terhadap gaya komunikasi diantara insinyur secara empiris menyimpulkan bahwasanya skill komunikasi terhadap para Insinyur sangat penting dalam meningkatkan motivasi kerja. Gaya komunikasi yang 
Prosiding The 1st National Conference on Applied Business, Education, \& Technology (NCABET)"

Unversitas Bina Bangsa 2021

DOI Article : 10.46306/ncabet.v1i1.30

berbeda-beda sangat erta kaitannya dengan kinerja karyawan, sehingga pemimpin perlu berhati-hati dalam melakukan komunikasi dengan bawahannya karena berdampak terhadap motivasi (Kundu et al, 2019). Hal ini diperkuat oleh Ciobanu et al (2019) dimana gaya komunikasi seorang pemimpin unutk memberikan perintah kepada bawahannya atas apa yang harus dikerjakan haruslah menggunakan metode komunikasi yang sesuai, jika gaya yang digunakan dalam bentuk controlling style maka yang terjadi adalah karyawan menjadi tidak tertarik karena akan merasa dipaksa untuk mematuhi atas pandangan yang disampaikan oleh atasan sehingga terkadang berbau kritikan dan bernada negatif.

Mengingat begitu pentingnya gaya komunikasi maka akan sangat menarik jika dikaji lebih mendalam pada industry otomotif mengingat industry otomotif memiliki struktur organisai atau hirarki yang berjenjang karena mempekerjakan banyak karyawan. Apakah indicator dan dimensi yang menjadi penyusun gaya komunikasi akan mampu berpengaruh terhadap motivasi kerja karyawannya serta seberapa besar pengaruhnya, sehingga diharapkan hasil penelitian akan mampu menjadi landasan teoritis bagi perusahaan dan level manajerial untuk dapat menerapkan hasil dari model penelitian yang diusulkan oleh peneliti.

Komunikasi memiliki fungsi yang terdiri komunikasi sebagai alat untuk menukar informasi dan membantu menghubungkan sekelompok anggota yang terdapat dalam organisasi yang saling terpisah dari anggota lainnya (Purwanto, 2011). Komunikais dapat terjadi memalui sebuah proses yang disebut sebagai proses komunikasi yang merupakan langkah-langkah dimulai dari saat menciptakan komunikasi hingga kepada dipahami oleh komunikan (Canggara, 2011) sebagaimana tergambar pada flowchart berikut ini:

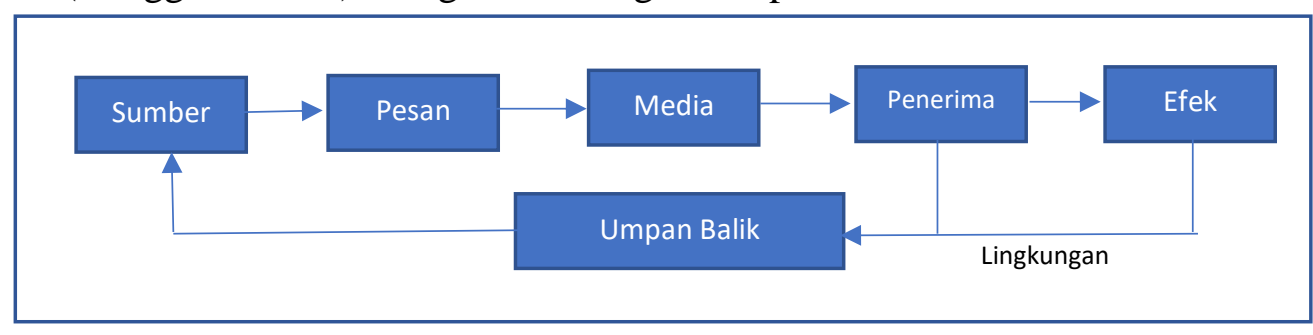

Gambar 1. Proses Komunikasi

Gaya komunikasi seorang atasan kepada bawahan akan membuat perubahan pada diri bawahannya, seperti menimbulkan gejala perasaan, kejiwaan dan emosi sehingga mendorong bawahannya untuk melakukan atau bertindak sesuatu sesuai dengan dorongan hatinya tersebut. Hal inilah yang menyebabkan gaya komunikasi menjadi sangat penting 
Prosiding The 1st National Conference on Applied Business, Education, \& Technology (NCABET)"

Unversitas Bina Bangsa 2021

DOI Article : 10.46306/ncabet.v1i1.30

dalam mencipatakan motivasi dalam sebuah tim yang pada akhirnya berpengaruh terhadap kinerja perusahaan (Haryati \& Kusumadewi, 2015). Motivasi akan menciptakan sebuah gairah kerja seseorang agar mau untuk bekerja sama, bekerja efektif, dan terintegrasi dengan segala daya dan upaya untuk mencapai kepuasan (Hasibuan, 2013).

Terdapat tiga model motivasi yang efektif untuk organisasi yang berbeda sesuai dengan budaya organisasinya masing-masing. Yang pertama adalah model tradisional (traditional model), dimana para manajer mendorong atau memotivasi tenaga kerja dengan cara memberikan imbalan berupa gaji atau upah yang makin meningkat. Kedua adalah model hubungan manusiawi (human relation model) dimana model ini lebih menekankan dan mengaggap penting terhadap faltor sosial yang dialami oleh seorang karyawan dalam bekerja dibandingkan dengan factor imbalan. Yang ketiga adalah model sumber daya manusia (human resources model) yang merupakan model akibat kritik terhadap model hubungan manusiawi dimana model sumber daya manusia lebih menekankan terhadap tanggung jawab bersama untuk mencapai tujuan organisasi dimana setiap karyawan berkontribusi kepada organisasi sesuai dengan tugas dan tanggung jawabnya masing-masing (Samsudin, 2010).

Penelitian ini menggunakan tiga dimensi anatar lain waktu penyampaian yang memiliki satu indikator yaitu apakah informasi disampaikan tepat waktu (GK1), dimensi metode dengan tiga indicator yaitu bahasa yang mudah dipahami (GK2), cara penyampaian yang sesuai (GK3) dan informasi yang disampaikan jelas dan singkat, serta dimensi yang ketiga yaitu respon yang terdiri dari indicator adanya timbal balik dari komunikan (GK4), adanya evaluasi setelah informasi disampaikan (GK5) dan bis amengutarakan dan menjelaskan informasi yang diterima (GK6) (Febrianita \& Hardjati, 2019; Hildwein, 2020; Kundu et al 2019). Sedangkan untuk motivasi kerja menggunakan dua dimensi, yang pertama adalah dimensi intrinsic yang memiliki indicator; terdapat peningkatan kualitas kerja karyawan (M1). Perubahan perilaku karyawan kearah yang lebih baik (M2), sense of belonging terhadap pekerjaan meningkat (M3), timbul inisiatif karyawan (M4) dan Karyawan menjadi pro aktif (M5). Sedangkan dimensi yang kedua adalah eksternal yang memiliki indicator; terciptanya suasana kerja yang lebih kondusif (M6), lebih mudah dalam menetapkan target (M7), timbulnya hubungan kerja yang lebih baik (M8)timbulnya semangat sebagai tim dalam menyelesaikan masalah (M9) dan bisa menerima masukan dan kritikan dari luar (M10) (Aliekperova, 2018; Dafruddin \& Heryanto, 2019; Hitka et al 2020). 


\section{METODE PENELITIAN}

Penelitian ini menggunakan pendekatan kuantitatif dengan paradigma berpikir deduktif menuju induktif dan menggunakan metode survey serta desain deskriptif kausalitas melalui Teknik analisis data SEM PLS serta alat bantu analisis Smart PLS 3.2.9 dengan menggunakan second order analisis. Variabel eksogen pada penelitian ini adalah gaya komunikasi sedangkan variabel endogennya adalah motivasi kerja.

Penelitian menggunakan 16 indikator dimana secara teoritis menurut Haire adalah Jumlah Indikator x 5 sehingga jumlah sampel yang dibutuhkan sebanyak 16x5=80 responden. Akan tetapi pada penelitian ini jumlah sampel yang digunakan sebanyak 166 responden agar dapat lebih menjawab fenomena yang terdapat pada tempat penelitian. Kriteria unit analisis yang digunakan adalah minimal sudah bekerja lebih dari 2 tahun pada posisi terakhir dan bertanggung jawab sebagai leader. Locus penelitian ini adalah perusahaan otomotif yang memiliki 6 plant berbeda di Kota Tangerang. Adapun kerangka penelitian awal yang diajukan adlah sebagai berikut:

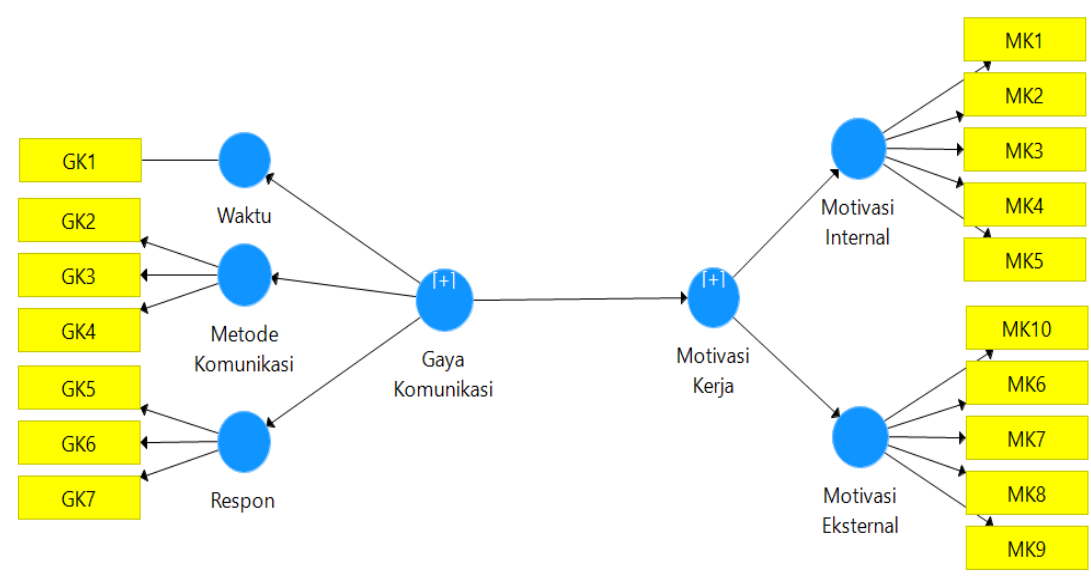

Gambar 2. Kerangka Penelitian

Hipotesis yang diujikan pada penelitian sebanyak enam hipotesis sebagai berikut; H1: Dimensi waktu penyampaian berpengaruh signifikan terhadap gaya komunikasi pada sektor industry otomotif di Kota Tangerang.

H2: Dimensi metode komunikasi berpengaruh signifikan terhadap gaya komunikasi pada sektor industry otomotif di Kota Tangerang.

H3: Dimensi respon berpengaruh signifikan terhadap gaya komunikasi pada sector industry otomotif di Kota Tangerang.

H4: Dimensi motivasi internal berpengaruh signifikan terhadap motivasi kerja pada sector industry otomotif di Kota Tangerang. 
Prosiding The 1st National Conference on Applied Business, Education, \& Technology (NCABET)" Unversitas Bina Bangsa 2021

DOI Article : 10.46306/ncabet.v1i1.30

H5: Dimensi motivasi eksternal berpengaruh signifikan terhadap motivasi kerja pada sector industri otomotif di Kota Tangerang.

H6: Gaya komunikasi berpengaruh signifikan terhadap motivasi kerja pada sector industry otomotif di Kota Tangerang.

Sequence analisis yang digunakan oleh peneliti tergambar pada flowchart di bawah ini .

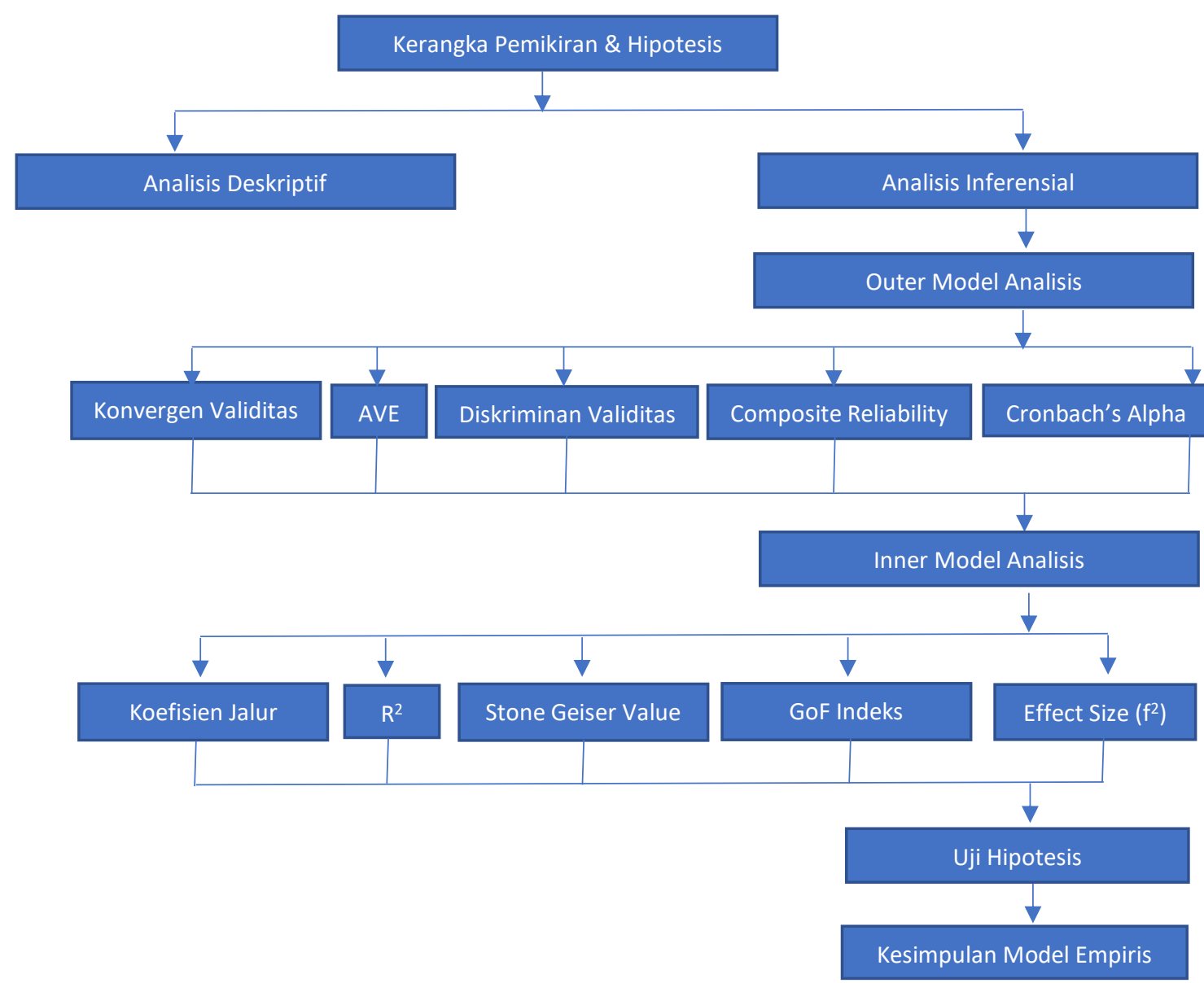

Gambar 3. Sequence Analisis Penelitian

\section{HASIL DAN PEMBAHASAN}

Hasil uji deskriptif terhadap demografi 160 responden didapatkan hasil sebagai berikut:

Tabel 1. Hasil Uji Deskriptif Responden

\begin{tabular}{|c|c|c|}
\hline Demografi & Frekuensi & Percent \\
\hline Jenis Kelamin & & \\
\hline Laki-Laki & 160 & $100 \%$ \\
\hline Perempuan & 0 & $0 \%$ \\
\hline
\end{tabular}


Prosiding The 1st National Conference on Applied Business, Education, \& Technology (NCABET)" Unversitas Bina Bangsa 2021

DOI Article : $10.46306 /$ ncabet.v1i1.30

\begin{tabular}{|c|c|c|}
\hline Total & $\mathbf{1 6 0}$ & $\mathbf{1 0 0 \%}$ \\
\hline Usia Responden & & $5 \%$ \\
\hline 18-23 Tahun & 39 & $24 \%$ \\
\hline $24-28$ tahun & 29 & $18 \%$ \\
\hline 29-34 Tahun & 10 & $6 \%$ \\
\hline 35-39 Tahun & 74 & $46 \%$ \\
\hline$>40$ tahun & $\mathbf{1 6 0}$ & $\mathbf{1 0 0 \%}$ \\
\hline Total & & $4 \%$ \\
\hline Pendidikan terakhir & 6 & $85 \%$ \\
\hline SMP Sederajat & 136 & $11 \%$ \\
\hline SMA Sederajat & 18 & $\mathbf{1 0 0 \%}$ \\
\hline Sarjana & $\mathbf{1 6 0}$ & $11 \%$ \\
\hline Total & 18 & $24 \%$ \\
\hline Masa Kerja & 30 & $13 \%$ \\
\hline 2-5 Tahun & 21 & $5 \%$ \\
\hline 6-10 Tahun & 8 & $46 \%$ \\
\hline $11-15$ Tahun & 74 & $\mathbf{1 0 0 \%}$ \\
\hline $16-20$ Tahun & $\mathbf{1 6 0}$ & \\
\hline$>20$ Tahun & & \\
\hline Total & & \\
\hline
\end{tabular}

Hasil outer model analisis terhadap model awal menggunakan parameter konvergen validitas melalui PLS Algorithm didapatkan nilai loading factor untuk variabel gaya komunikasi terdapat 1 indikator yang tidak valid karena nilai loading factor $<0,70$ yaitu GK6. Sedangkan untuk variabel motivasi kerja terdapat 2 indikator yang tidak valid yaitu MK 6 dan MK 10 karena loading factor $<0,70$. Sehingga ketiga indicator tersebut di droping dari model awal dan menjadi model ke-2. Hasil analisis outer model kedua didapatkan hasil sebagai berikut:

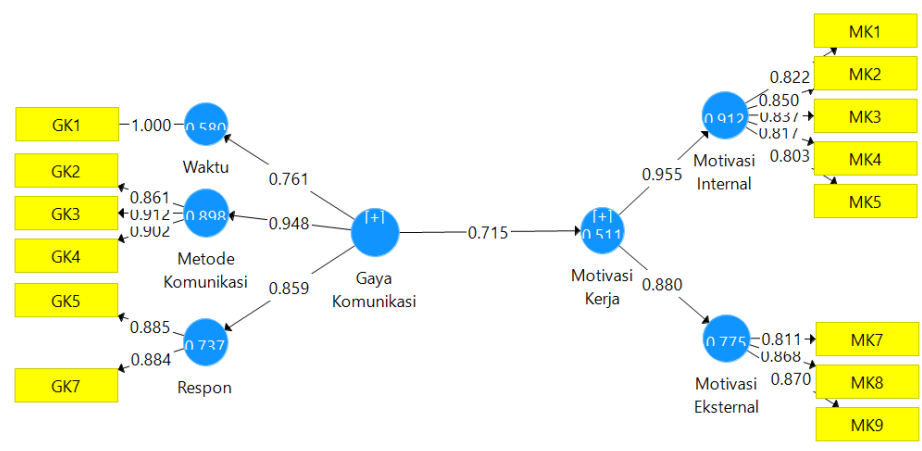

Gambar 4. Hasil Outer Model Analisis Ke-2

Dari hasil outer model analisis ke-2 terhadap parameter konvergen validitas di dapatkan nilai loading factor untuk ke 6 indikator dari variabel gaya komunikasi telah > 0,70. Sedangkan untuk motivasi kerja telah dengan 8 indikator telah memiliki nilai loading factor $>0,70$. Berdasarkan hasil tersebut dapat diinterpretasikan bahwa seluruh indicator dari variabel eksogen dan variabel endogen telah valid yang artinya masingmasing indicator mampu dijadikan alat ukur untuk menjawab fenomena yang dianalisis. Hasil uji konvergen validitas diperkuat dengan hasil uji diskriminan validitas dimana nilai 
Prosiding The 1st National Conference on Applied Business, Education, \& Technology (NCABET)"

Unversitas Bina Bangsa 2021

DOI Article : 10.46306/ncabet.v1i1.30

loading factor untuk ke 14 indikator lebih besar dibandingkan dengan nilai cross loadingnya. Hasil uji validitas dan reliabilitas selanjutnya adalah Average Variance Extracted (AVE), composite reliabilitas (CR) dan alpha cronbach's didapatkan nilai sebagai berikut:

Tabel 2. Hasil Uji AVE, CR dan Alpha Chronbach's Model Ke-2

\begin{tabular}{|l|c|c|c|}
\hline & AVE & CR & Cronbach's Alpha \\
\hline Waktu Penyampaian & 1,000 & 1,000 & 1,000 \\
\hline Metode Komunikasi & 0,795 & 0,921 & 0,871 \\
\hline Respon & 0,782 & 0,878 & 0,722 \\
\hline Gaya Komunikasi & 0,646 & 0,916 & 0,889 \\
\hline Motivasi Internal & 0,682 & 0,915 & 0,884 \\
\hline Motivasi Eksternal & 0,722 & 0,886 & 0,807 \\
\hline Motivasi Kerja & 0,598 & 0,922 & 0,904 \\
\hline
\end{tabular}

Dari hasil tabel 2 dapat diinterpretasikan bahwasanya AVE dari dimensi gaya komunikasi yang terdiri dari waktu penyampaian, metode komunikasi dan respon memiliki nilai AVE > 0,50. Dari hasil tersebut maka dapat diinterpretasikan bahwasanya nilai varians dari masing-masing indicator dalam konstruk yang ditangkap oleh variabel tersebut lebih besar dibandingkan dengan nilai varians yang berasal kesalahan pengukuran. Sama halnya juga dengan nilai AVE untuk masing-masing dimensi motivasi internal dan motivasi eksternal didapatkan nilai AVE > 0,50 yang menggambarkan seluruh dimensi pada model penelitian valid karena memiliki nilai error penelitian lebih kecil dibandingkan dengan error dari kesalahan pengukuran. Sedangkan untuk variabel gaya komunikasi memiliki nilai AVE 0,646 dan motivasi kerja memiliki nilai 0,598 dimana nilai tersebut $>0,50$ sehingga secara structural indicator dan dimensi yang digunakan untuk mengukur masing-masing variabel laten memiliki varians yang baik.

Hasil uji CR dari indicator masing-masing dimensi waktu penyampaian, metode komunikasi dan respon memiliki nilai $\mathrm{CR}>0,70$ dimana nilai ini menggambarkan konsistensi yang reliabel. Sama halnya juga untuk indikator dari dimensi internal dan dimensi eksternal, memiliki nilai $\mathrm{CR}>0,70$ dimana hal tersebut menggambarkan konsistensi dari indicator dan dimensi yang digunakan untuk mengukur variabel latennya. Untuk memperkuat hasil CR, maka dilanjutkan dengan uji alpha chronbach's dimana nilai alpha chronbach's untuk masing-masing indicator dan dimensi didapatkan > 0,60 yang menggamabrkan konsistensi yang baik. Dari kelima parameter outer model analisis, didapatkan seluruh parameter telah sesuai dengan yang dipersyaratkan sehingga unutk selanjutnya dilakukan inner model analisis dengan menggunakan PLS Bootstraping dan didapatkan hasil sebagai berikut:

Tabel 3. Hasil Inner Model Analisis Model Ke-2 
Prosiding The 1st National Conference on Applied Business, Education, \& Technology (NCABET)" Unversitas Bina Bangsa 2021

DOI Article : $10.46306 /$ ncabet.v1i1.30

\begin{tabular}{|l|c|c|c|}
\hline & $\begin{array}{c}\text { Path } \\
\text { Coefficient }\end{array}$ & $\begin{array}{c}\text { T } \\
\text { Statistic }\end{array}$ & $\begin{array}{c}\text { P } \\
\text { Values }\end{array}$ \\
\hline Gaya Komunikasi $\rightarrow$ Waktu Penyampaian & 0,761 & 16,292 & 0,000 \\
\hline Gaya Komunikasi $\rightarrow$ Metode Komunikasi & 0,948 & 117.401 & 0,000 \\
\hline Gaya Komunikasi $\rightarrow$ Respon & 0,859 & 37,775 & 0,000 \\
\hline Motivasi Kerja $\rightarrow$ Motivasi Internal & 0,955 & 129,181 & 0,000 \\
\hline Motivasi Kerja $\rightarrow$ Motivasi Eksternal & 0,880 & 41,029 & 0,000 \\
\hline Gaya Komunikasi $\rightarrow$ Motivasi Kerja & 0,715 & 16,989 & 0,000 \\
\hline
\end{tabular}

Hasil inner model analisis di atas dapat diinterpretasikan untuk variabel gaya komunikasi yang paling dominan adalah dimensi metode komunikasi dengan koefisien jalur paling besar yaitu 0,948 sedangkan untuk dimensi waktu penyampaian sebesar 0,761 dan dimensi respon sebesar 0,859. Dari hasil tersebut maka didapatkan persamaan structural untuk variabel laten gaya komunikasi sebagai berikut:

$$
\eta_{1}=0,761 \varepsilon_{1}+0,948 \varepsilon_{2}+0,859 \varepsilon_{3}+e
$$

Sedangkan untuk hasil koefisien jalur variabel laten motivasi kerja didominasi oleh dimensi motivasi internal dengan nilai koefisien jalur sebesar 0,955. Adapun untuk nilai koefisien jalur dimensi motivasi eksternal sebesar 0,880. Dari hasil tersebut maka didapatkan persamaan structural untuk variabel laten motivasi kerja sebagai berikut:

$$
\eta_{2}=0,955 \varepsilon_{4}+0,880 \varepsilon_{5}+e
$$

Hasil koefisien jalur variabel gaya komunikasi terhadap motivasi kerja didapatkan nilai koefisien jalur sebesar 0,715. Nilai koefisien jalur tersebut masuk kedalam kategori tinggi dari sebuah prediktor terhadap criterionnya. Sehingga dapat dikatakan bahwasanya gaya komunikasi merupakan variabel prediktor yang esensial bagi motivasi kerja, dengan bentuk persamaan structural gaya komunikasi terhadap motivasi kerja sebagai berikut:

$$
n_{3}=0,890 \varepsilon_{6}+e
$$

Hasil $\mathrm{R}$ square $\left(\mathrm{R}^{2}\right)$ dari masing-masing dimensi dan juga variabel laten didapatkan secara keseluruhan termasuk kategori sedang dimana terangkum pada tabel 4. Dengan besarnya nilai $\mathrm{r} 2$ variabel motibasi kerja sebesar 0,511 sehingga didapatkan nilai koefisien determinasi (KD) sebesar 51,1\% yang artinya variabel motivasi kerja dipengaruhi oleh variabel gaya komunikasi sebesar $51,1 \%$ sedangkan sisanya sebesar $48,9 \%$ dipengaruhi oleh variabel lainnya diluar model yang diujikan.

Tabel 4. Nilai R2 dan R2 Adjusted Model Ke-2

\begin{tabular}{|l|c|c|}
\hline & R Square & R Square Adjusted \\
\hline Waktu Penyampaian & 0,580 & 0,577 \\
\hline Metode Komunikasi & 0,898 & 0,897 \\
\hline Respons & 0,737 & 0,736 \\
\hline Motivasi Internal & 0,912 & 0,911 \\
\hline
\end{tabular}


Prosiding The 1st National Conference on Applied Business, Education, \& Technology (NCABET)"

Unversitas Bina Bangsa 2021

DOI Article : 10.46306/ncabet.v1i1.30

\begin{tabular}{|l|c|c|}
\hline Motivasi Eksternal & 0,775 & 0,774 \\
\hline Motivasi Kerja & 0,511 & 0,508 \\
\hline
\end{tabular}

Hasil uji terhadap parameter GoF Indeks dengan menggunakan persamaan $\sqrt{R 2 \times A V E}$ didapatkannilai sebesar 0,617 dimana nilai ini masuk kedalam kategori tinggi yang menggambarkan model penelitian yang dibangun memiliki tingkat kecocokan yang tinggi dan tidak terdapat perbedaan (discrepancy) antara nilai yang diobservasi dengan nilai yang diharapkan dalam model penelitian. Hasil uji terhadap parameter Stone Geiser Value (Q2) untuk variabel motivasi kerja sebesar 0,300 dimana nilai ini > 0 yang menggambarkan nilai predictive relevance yang baik dimana masing-masing dimensi sebagai prediktor dari variabel latennya mampu memprediksi variabel laten yang dibangunnya. Gaya komunikasi sebagai variabel eksogen mampu memprediksi variabel endogennya dengan baik. Secara detail nilai masing-masing predictive relevance terangkum pada tabel 5 berikut ini:

Tabel 5. Nilai Predictive Relevance Model Ke-2

\begin{tabular}{|l|c|c|c|}
\hline & SSO & SSE & Q2 (=1-SSE/SSO) \\
\hline Waktu Penyampaian & 160.000 & 69,290 & 0,567 \\
\hline Metode Komunikasi & 480.000 & 139.777 & 0.709 \\
\hline Respon & 320.000 & 137.439 & 0,571 \\
\hline Motivasi Internal & 800.000 & 309.641 & 0.631 \\
\hline Motivasi Eksternal & 480.000 & 214.800 & 0.552 \\
\hline Gaya Komunikasi & 960.000 & 960.000 & \\
\hline Motivasi Kerja & 1280.000 & 896.199 & 0.300 \\
\hline
\end{tabular}

Hasil parameter ujji inner model analisis yang terakhir dengan menggunakan effect size (f2) didapatkan seluruh dimensi memiliki kategori strong effect secara parsial mengingat hasil yang didaptkan > 0,40 dimana peneliti menggunakan acuan Cohen (1988). Hasil tersebut menggambarkan pengaruh dari masing-masing dimensi terhadap variabel latennya secara pasrsial memiliki pengaruh yang kuat. Sebagaimana dapat dilihat pada tabel berikut:

Tabel 6. Nilai Effect Size (f2) Model Ke-2

\begin{tabular}{|l|c|c|}
\hline & $\begin{array}{c}\text { Gaya } \\
\text { Komunikasi }\end{array}$ & $\begin{array}{c}\text { Motivasi } \\
\text { Kerja }\end{array}$ \\
\hline Waktu Penyamapaian & 1.379 & \\
\hline Metode Komunikasi & 8,794 & \\
\hline Respon & 2,808 & 1,045 \\
\hline Gaya Komunikasi & & 10,327 \\
\hline Motivasi Internal & & 3,444 \\
\hline Motivasi Eksternal & & \\
\hline
\end{tabular}

Hasil uji hipotesi sebagaimana terangkum pada tabel 3 di atas terhadap rangkuman nilai P Values dan T Statistik dapat diinterpretasikan sebagai berikut. Untuk hipotesis pertama terkait pengaruh waktu penyampaian terhadap gaya komunikasi didapatkan nilai P Values sebesar $0,000<$ probability 0,05 dan T Statistik 16,292 > 1,96 
Prosiding The 1st National Conference on Applied Business, Education, \& Technology (NCABET)"

Unversitas Bina Bangsa 2021

DOI Article : 10.46306/ncabet.v1i1.30

sehingga hipotesis pertama diterima, yang artinya terdapat pengaruh signifikan waktu penyampaian terhadap gaya komunikasi, Hasil uji hipotesis kedua terkait pengaruh metode komunikasi terhadap gaya komunikasi didapatkan nilai P Values sebesar 0,000< probability 0,05 dan nilai T Statistik 117,401 > 1,96 sehingga hipotesis kedua diterima yang artinya terdapat pengaruh signifikan metode komunikasi terhadap gaya komunikasi. Hasil uji hipotesis ketiga terkait pengaruh respon terhadap gaya komunikasi didapatkan nilai $\mathrm{P}$ Values sebesar $0,000<$ probability 0,05 dan nilai $\mathrm{T}$ Statistik 37,775 > 1,96 sehingga hipotesis diterima yang artinya terdapat pengaruh signifikan respon terhadap gaya komunikasi.

Hasil uji hipotesis keempat terkait pengaruh motivasi internal terhadap motivasi kerja didaptkan nilai $\mathrm{P}$ Values sebesar $0,000<$ probability 0,05 dan nilai $\mathrm{T}$ Statistik $129,181>1,96$ sehingga hipotesis diterima yang artinya terdapat pengaruh signifikan motivasi internal terhadap motivasi kerja. Hasil uji hipotesis kelima terkait pengaruh motivasi eksternal terhadap motivasi kerja didapatkan nilai $\mathrm{P}$ Values $0,000<$ probability 0,05 dan nilai T Statistik 41,029 > 1,96 sehingga hipotesis kelima diterima yang artinya terdapat pengaruh signifikan motivasi eksternal terhadap motivasi kerja. Sedangkan hipotesis keenam terkai pengaruh gaya komunikasi terhadap motivasi kerja didapatkan nilai $\mathrm{P}$ Values sebesar 0,000 < probability 0,05 dan nilai $\mathrm{T}$ Statistik 16,989 > 1,96 sehingga hipotesis diterima yang artinya terdapat pengaruh signifikan gaya komunikasi terhadap motivasi kerja.

Berdasarkan hasil penelitian di atas didapatkan karyawan pada lokus penelitian didapatkan dimensi metode komunikasi menjadi dominator dibandingkan dimensi waktu dan respon. Hal tersebut menggambarkan bahwasanya metod ekomunikais merupakan hal yang paling menjadi fokus para karyawan. Metode komunikasi yang dapat digunakan pada berbagai macam organisasi tentunya berbeda-beda sesuai dengan jenis organisasi dan lingkungan organisasi tersebut. Namun secara teori, terdapat enam jenis metode komunikasi yang dapat dipilih sebagai berikut.

The controlling style yaitu gaya komunikasi yang bersifat mengendalikan kehendak dengan maksud membatasi dan memaksa orang yang diajak berkomunikasi. The equalitarian style yaitu gaya komunikasi yang mementingkan arah komunikasi menjadi aktif karena bersifat dua arah, dimana penerima pesan diberi keleluasaan untuk berinteraksi dengan pemberi pesan. The structuring style yaitu gaya komunikasi yang memanfaatkan pesan-pesan verbal secara tertulis mauoun lisan untuk menekankan 
perintah terhadap hal-hal yang harus dilaksanakan. The dynamic style yaitu gaya komunikasi dinamis dan memiliki kecendrungan agresif dimana pengirim pesan memahami bahwasanya lingkungan organisasi berorientasi pada tindakan. The Withdrawal style yaitu gaya komunikasi yang digunakan adalah melemahnya tindak komunikasi, artinya tidak ada keinginan dari orang-orang yang memaknai gaya komunikasi ini dengan orang lain (Tubbs \& Moss, 2008).

Sedangkan untuk variabel motivasi kerja didominasi oleh dimensi internal, hal ini menggambarkan bahwasanya dimensi internal yang merupakan dorongan yan timbul dari dalam hati seseorang tanpa memerlukan rangsangan dari luar, dibandingkan dengan motivasi eksternal yaitu dorongan yang timbul akibat adanya rangsangan dari luar. Dari pernyataan tersebut maka dapat disimpulkan bahwasanya dorongan terhadap peningkatan kualitas kerja, perubahan perilaku, senese of belongin, inisitaif dan pro aktif karyawan menjadi dominan pada karyawan yang bergerak di sector industry otomotif.

Hasil penelitian ini sejalan dengan penelitian Haryati \& Kesumadewi (2015) dimana gaya komunikasi dapat menimbulkan dorongan yang kuat terhadap motivasi karyawan sehingga sebaiknya perusahaan memperhatikan komunikasi yang terjalin antara karyawan dengan pimpinan, agar dapat tercipta keselarasan dalam perusahaan. Sedangkan Pertiwi (2016) didapatkan bahwasanya keterikatan antara satu karyawan dengan karyawan yang lain maupun atasannya didukung dengan adanya gaya komunikasi akan meningkatkan kinerja karyawan. Komunikasi membantu perkembangan motivasi dengan menjelaskan kepada para karyawan apa yang harus dilakukan, bagaimana bekerja dengan baik, dan apa yang dapat dikerjakan untuk memperbaiki kinerjanya (Shintia \& Rachmiyati, 2016).

\section{KESIMPULAN}

Berdasarkan hasil penelitian yang telah dilakukan, didapatkan dimensi metode komunikasi menjadi yang paling dominan terhadap variabel eksogen gaya komunikasi sedangka dimensi motivasi internal menjadi dimensi yang dominan terhadap motivasi kerja. Dari enam hipotesis yang diujikan, didapatkan seluruh hipotesis diterima, yang artinya terdapat pengaruh signifikan dari dimensi penyusun variabel laten terhadap masing-masing variabel latennya. Gaya komunikasi berpengaruh signifikan terhadap motivasi kerja dengan besarnya pengaruh sebesar 51,1\% sedangkan sisanya dipengaruhi oleh variabel lainnya diluar model yang diujikan. 
Prosiding The 1st National Conference on Applied Business, Education, \& Technology (NCABET)"

Unversitas Bina Bangsa 2021

DOI Article : 10.46306/ncabet.v1i1.30

Gaya komunikasi memegang peranan penting dalam mendorong terciptanya motivasi kerja, sehingga akan terbentuk hubungan yang harmonis antara atasan dengan karyawan dan sesame karyawan. Model yang diujikan memiliki nilai predictive relevance yang tinggi yang artinya dimensi dan variabel eksogen mampu memprediksi variabel endogennya dengan baik.

\section{UCAPAN TERIMA KASIH}

Penulis mengucapkan terima kasih yang sebesar-besar kepada Prof. Masyhudzulhak Djamil, Prof. Ngadino Surip, Prof. Pantja Djati, Prof, Mudrik Alaydrus, Prof. Apollo Daito, Prof. Willy Arafah dan Prof. Suparmoko yang telah banyak membimbing penulis selama ini dan menjadi sumber inspirasi serta panutan bagi penulis. Tidak lupa juga kami ucapkan terima kasih kepad Tim Panitia NCBET yang telah menginisiasi acara.

\section{DAFTAR PUSTAKA}

Aliekperova, Nataliia. 2018. "Motivating Factors Effecting Work Efficiency of Empoyees in Ukrainian Pharmaceutical Sector." Economics \& Sociology 11(1):6174. doi: 10.14254/2071-789X.2018/11-1/4.

Canggar, H. 2011. Pengantar Ilmu Komunikasi. Cetakan Ketiga Belas. Jakarta: Rajawali Perss.

Ciobanu, Alina, Armenia Androniceanu, and George Lazaroiu. 2019. "An Integrated Psycho-Sociological Perspective on Public Employees' Motivation and Performance." Frontiers in Psychology. 1-7. doi: 10.3389/fpsyg.2019.00036.

Dafruddin, \& Heryanto. 2019. The Effect of Work Motivation and Work Environment on Performance With Satisfaction as Intervening Variables Education Personnel Rektorate Andalas University. Archives of Business Research. 7(2):103-20. doi: 10.14738/abr.72.5768

Febrianita, R., \& Hardjati, S. 2019. The Power of Interpersonal Communication Skill in Enhancing Service Provision. Journal of Social Science research. 14. 3192-3199.

Haryati, E., \& Kesumadewi. 2015. Pengaruh Motibasi Terhadap Motivasi Kerja karyawan Pada PT. Swasti Tunggal Mandiri Medan. Jurnal Bisnis Administrasi. 4(1). 86-99.

Hasibuan, M.S.P. 2012. Manajemen Sumber Daya Manusia. Cetakan Ketujuh Belas, Jakarta: PT. Bumi Aksara.

Hildwein, F. 2020. How Communicative Performance Can Constitute an Organization's Self. Journal Management. 23(1). 61-80.

Hitka, M., Kozubikova, L., \& Marek Potkany, M. 2018. Education and Gender Based Differences in Employee Motivation. Journal of Business Economics and Management. 19(1). 80-95. doi: 10.3846/16111699.2017.1413009.

Karima, A.N.A., Idayanti, Umar,A. 2018. Effect of the Work Training and Motivation to Employee Productivity at PT. Bank Sulsebar. 49-64

Kundu, Subhash C., Sandeep Kumar, and Neha Gahlawat. 2019. "Empowering Leadership and Job Performance: Mediating Role of Psychological Empowerment." 
Management Research Review 42(5):605-24. doi: 10.1108/MRR-04-2018-0183.

Mehta, Nikhil, K., Jha, S. 2020. Facilitation of Team Communication Skill Among Engineers: An Empirical Study. Higher Education Skill and Work Based Learning ahead-of-p(ahead-of-print). doi: 10.1108/HESWBL-04-2019-0055.

Nuryanto, U.W., Djamil, M., Sutawidjaya, A.H., \& Saluy, S.B. 2020. Strategi Peningkatan Kinerja Dosen Melalui Pengembangan Dimensi Modal Sosial Pada Perguruan Tinggi Swasta (Studi Kasus Perguruan Tinggi Swasta di Kota Serang). Jurnal Mandiri, Ilmu Pengetahuan, Seni dan Teknologi. 4 (1). 14-25.

Obi, O. 2018. Influence of Leader Communication on Employee Motivation. ProQuest Dissertations and Theses. 139.

Pertiwi, E.D. 2016. Pengaruh Gaya Kepemimpinan, Komunikasi Internal, Motivasi dan Disiplin Kerja Terhadap Kinerja Karyawan (Studi Kasus Pada PT. Gujati 59 Utama Sukoharjo). Universitas Muhammadiyah Surakarta. 1-14.

Purwanto, D. 2013. Komunikasi Bisnis. Edisi Keempat. Jakarta: PT, Gelora Aksara Pratama.

Shintia, N., \& Rachmiyati. 2020. Pengaruh Gaya Kepemimpinan, Komunikasi dan Motivasi Kerja Terhadap Kinerja PNS Pada Politeknik Negeri Banjarmasin. Jurnal INTEKNA. 16(2). 184-200.

Tasya, I.A., \& Gilang, A. 2020. The influence of Motivation on Employee Performance. Journal of Chemical Information and Modeling. 53(9). 1688-1699.

Tubbs, L.S., \& Moss, S. 2008. Human Communication: Prinsip-Prinsip Dasar. Bandung: PT. Remaja Rosdakarya.

Usman, S. 2020. Pasar Mobil Indonesia Terbesar di Asia Tenggara. Available online: Tahun Lalu Industri Otomotif Sumbang Rp 260,9 Triliun ke GDP Indonesia Halaman $2 \mid$ merdeka.com (accessed on 24 September 2021) 